TAO, Vol. 16, No. 3, 579-594, August 2005

\title{
Modern Seismic Observations in the Tatun Volcano Region of Northern Taiwan: Seismic/Volcanic Hazard Adjacent to the Taipei Metropolitan Area
}

\author{
Kwang-Hee Kim ${ }^{1,2, *}$, Chien-Hsin Chang $^{3}$, Kuo-Fong Ma ${ }^{1}$, Jer-Ming Chiu ${ }^{4}$ \\ and Kou-Cheng Chen ${ }^{2}$
}

(Manuscript received 22 November 2004, in final form 21 June 2005)

\begin{abstract}
The Tatun volcano group is located adjacent to the Taipei metropolitan area in northern Taiwan and was a result of episodic volcanisms between 2.8 and 0.2 Ma. Earthquake data collected over the last 30 years are analyzed to explore seismicity patterns and their associated mechanisms of faulting in the area. Using a Joint Hypocenter Determination (JHD) method, a few sequences of relocated earthquake hypocenters are tightly clustered; these seemed to be blurry in the original catalog locations. Numerous earthquakes, previously unnoticed and not reported in the CWB catalog, have been identified from careful examination of the continuous recordings of a nearby broadband seismic station. These newly identified earthquakes show similarities in waveforms and arrival time differences between direct $\mathbf{P}$ - and $\mathrm{S}$-waves indicating that their hypocenter locations are very close to each other and their source mechanisms are similar. A relatively high b-value of 1.22 is obtained from the analysis of crustal earthquakes (depth $<30 \mathrm{~km}$ ) in the region, which may suggest that clustered local seismicity in the Tatun volcanic region probably resulted from subsurface hydrothermal or volcano-related activities. Focal mechanism solutions determined in this study are dominated by normal faulting. Thus, these earthquake clusters are most probably associated with hydrothermal/magmatic activities in a back-arc extensional environment.
\end{abstract}

${ }^{1}$ Institute of Geophysics, National Central University, Chung-Li, Taiwan, ROC

2 Institute of Earth Sciences, Academia Sinica, Taipei, Taiwan, ROC

${ }^{3}$ Central Weather Bureau, Taipei, Taiwan, ROC

${ }^{4}$ Center for Earthquake Research and Information, The University of Memphis, Memphis, USA

* Corresponding author address: Dr. Kwang-Hee Kim, Institute of Earth Sciences, Academia Sinica, Taipei, Taiwan, ROC;E-mail: kim@earth.sinica.edu.tw 
(Key words: Seismic/Volcanic Hazard, Tatun Volcano Group, Taipei metropolitan area, Joint Hypocenter Determination, Waveform Similarity, Earthquake Swarm, B-value.)

\section{INTRODUCTION}

Tatun volcano group in northern Taiwan is located behind the consuming plate margin where the Philippine Sea plate is subducting beneath the Eurasian plate. The study region consists of the Tatun Mountain (1,081 m above sea level at its peak) and 20 other volcanic domes in the surrounding area at the northern end of Taiwan (Fig. 1). Volcanism in this region ceased in the Pliocence (Ho 1988; Song et al. 2000) and the region is considered inactive at present. However, frequently observed hot springs, gas fumaroles, and lower magnitude background seismicity with occasionally moderate-sized earthquakes suggest otherwise. Thus, the volcano group may pose a serious hazard to life and property in the surrounding areas including the Taipei metropolitan area with a population of more than 6.7 million.

In this study we investigate seismological features of the Tatun volcanic region using various earthquake data collected over the last 30 years of modern seismic monitoring. A Joint Hypocenter Determination (JHD) technique (Pujol 1988; 1995; 2000) is applied to obtain relatively reliable earthquake locations. After careful examination of continuously recorded data at a nearby broadband station, a few sequences of swarm-type seismicity have been identified that were not obvious in the earthquake catalog of the Central Weather Bureau (CWB). We also compare b-values between the Tatun volcano area and the entire island of Taiwan to determine if swarm-type seismicity is persistent. Finally, we discuss potential mechanisms of seismicity in the region based on a few focal mechanisms.

\section{TECTONIC BACKGROUND}

One of the most active tectonic processes on earth can be observed near the island of Taiwan where three plates - the Eurasian plate, the Philippine Sea plate, and the South China Sea plate - are converging (Tsai 1986). Most prominent seismic and tectonic features in the Taiwan region are closely related to a collision system sandwiched between two active subduction systems, one in northeastern and the other in southern Taiwan. The Philippine Sea plate and the Eurasian plate are colliding obliquely in the central eastern Taiwan at a high convergence rate of $82 \mathrm{~mm} \mathrm{yr}^{-1}$ (Yu et al. 1997), which is responsible for the mountain building processes and the $\mathrm{N}-\mathrm{S}$ trending geologic and tectonic configurations in the Taiwan region. Taiwan orogeny is relatively young in a geologic time scale. Evidences from the study of sedimentation rates and paleomagnetism indicate that the mountain building process in the Taiwan region started about 5 million years ago (Suppe 1984). Recently, a high rate of crustal deformation has been observed by a series of leveling and GPS observations (Yu and Liu 1989; Angelier et al. 1997; Yu et al. 1997). Due to the high rate of plate convergence and significant plate deformation, seismicity in the Taiwan region is one of the highest in the world. The northwest dipping Wadati-Benioff zone in northern Taiwan has been recognized since the beginning of modern seismic monitoring (early 1970's ) in the Taiwan region (Tsai 1986). 


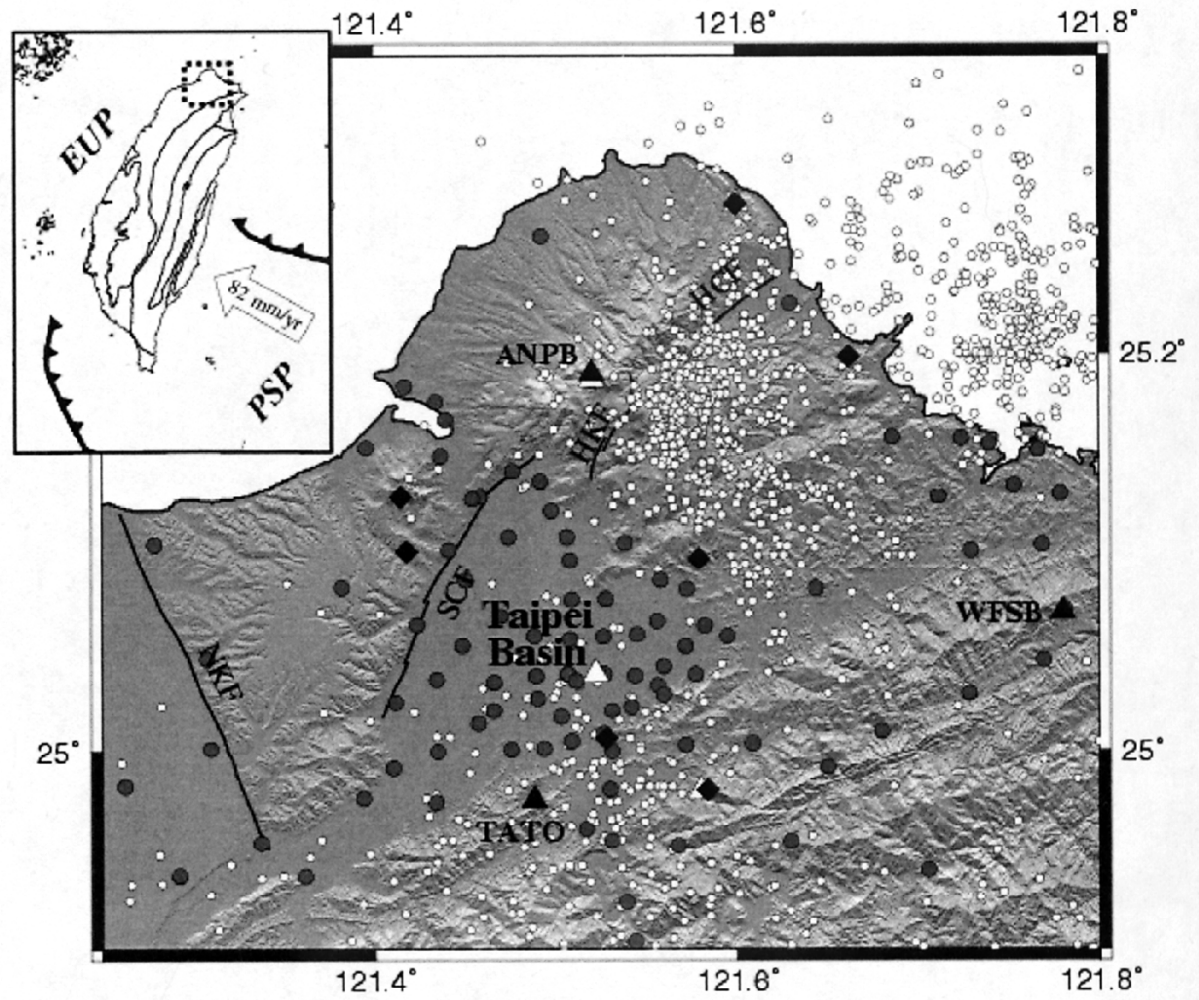

Fig. 1. Locations of seismic stations operated by various seismic networks and earthquake epicenters on top of topography map in the study area. The city of Taipei is located in the Taipei basin adjacent to the Tatun volcano group. Earthquake epicenters with magnitude greater than 2.0 between 1973 and 2003 are shown by open circles. Earthquake parameters are determined by TTSN-IES or TSN-CWB. Concentrated seismicity to the north and northeast of Taipei basin can be associated with the Tatun volcano group. TTSN-IES short period seismic stations, TSN-CWB short period seismic stations, TSMIP strong motion stations, and BATS broadband stations are shown as solid diamonds, open triangles, gray circles, and solid triangles, respectively. Locations of active fault (Lee 1999) are shown by solid lines including: HCF: Huangchi fault, HKF: Hsiaoyukeng fault, SCF: Sanchiao fault, and NKF: Nankan fault. The study area is marked by a rectangle with broken lines shown in the index map. The index map also shows NS-trending major geologic divisions in Taiwan. High convergence rate $\left(82 \mathrm{~mm} \mathrm{yr}^{-1}\right)$ and its direction are determined from GPS observations between 1990 and 1995 (Yu et al. 1997). EUP: Eurasian Plate, PSP: Philippine Sea Plate. 
The Quaternary arc volcanism of Tatun volcano group and several offshore volcanic islets are the volcanic arcs associated with the subduction of the Philippine Sea plate beneath the Eurasian plate (Tsai et al. 1981; Suppe 1984). Lava flows with minor pyroclastic rocks are dominant in the Tatun volcano region. Based on regional geology, gravity, and borehole data, Song et al. (2000) constructed a volcanic evolution model to interpret characteristic features of regional volcanisms in the Tatun volcano region. Their model suggests that eruptions in the Tatun volcano group commenced at about 2.8 to $2.5 \mathrm{Ma}$ in a compressional tectonic environment during the accretion and oblique collision between the Luzon arc and the China continental margin. Volcanism was not significant for a long time period between 2.5 to $0.8 \mathrm{Ma}$. Northern Taiwan has experienced changes of stress environment at about $0.8 \mathrm{Ma}$ due to the opening of the Okinawa Trough or the post-collision extensional collapse. Then, a large amount of andesitic lavas erupted to form large volcanoes between 0.8 to $0.2 \mathrm{Ma}$. Currently, widely distributed hydrothermal activities and gas fumaroles, and frequently observed clustered small magnitude earthquakes suggest that volcanic activity in the Tatun volcano region may have persisted continuously since the last eruption at $0.2 \mathrm{Ma}$.

\section{DATA AND METHOD}

Earthquake data used in this study has been selected from four different sources (Fig. 1) including (1) the Taiwan Telemetered Seismographic Network (TTSN), (2) the Taiwan Seismic Network (TSN), (3) the Broadband Array in Taiwan for Seismology (BATS), and (4) the Taiwan Strong Motion Instrumentation Program (TSMIP). Analyses of available data from different seismic networks are briefly outlined in this section. The TTSN, which consisted of 24 stations, was operated from 1973 to 1990 by the Institute of Earth Sciences (IES), Academia Sinica. Some of the TTSN stations were relocated during this period and eventually the total number of sites occupied by the network increased to 35. Most TTSN stations were equipped with vertical-component velocity-type sensors, although horizontal sensors were added to a few stations after 1983. The TTSN was upgraded and expanded in 1991 to become an advanced island-wide seismic network, i.e., the TSN, and maintained by the Central Weather Bureau (CWB) of Taiwan. The TSN consists of 753 -component short-period seismic stations covering the entire Taiwan region. The TSN has provided significant improvement in spatial coverage and spatial resolution of seismic monitoring regionally; however, it has probably provided poorer spatial coverage of the Tatun region than the TTSN since several TTSN stations were closed at the merger. Therefore, we used P- and S-wave arrival time data recorded by TTSN to take advantage of better station coverage in the study area before 1990. Selected earthquake data recorded by the TTSN have been relocated using the JHD technique (e.g., Pujol 1988, 1995, 2000) to improve the resolution of relative earthquake locations. The JHD method provides better relative earthquake hypocenters with a minimum affect by the choice of velocity model. The possible errors in travel times due to the over-simplified earth model are presented in terms of $\mathrm{P}$ - and S-wave JHD station corrections. Hypocenters and individual station corrections are simultaneously determined.

The TSMIP was installed and has been operated by the CWB since 1991 to monitor strong 
ground motions in the major metropolitan areas of Taiwan with about 600 free field strong motion stations and a few building and bridge strong motion arrays. Therefore, focal mechanisms for the selected larger earthquakes in the Tatun region can be better determined with the addition of data from the nearby TSMIP stations.

Continuous waveform data recorded by the BATS have also been reviewed to investigate micro-seismicity not detectable by other networks in the study region. The BATS are composed of 15 permanent and 15 portable broadband stations covering the entire Taiwan region. Data Management Center (DMC) at IES exerts tremendous effort to record signals from all the BATS stations continuously and make them available on request via DMC-IES or DMCIRIS (Incorporated Research Institutions for Seismology). Continuous waveform data from three BATS stations near the Tatun volcanic region have been inspected to explore micro tremors associated with hydrothermal activities.

\section{RESULTS AND DISCUSSIONS}

\subsection{JHD Analysis of TTSN Data}

343 earthquakes recorded by more than 4 stations with good azimuthal coverage are selected from the TTSN catalog. These earthquakes were relocated using the JHD technique with the total number of earthquakes being reduced to 262 after 6 iterations. Some earthquakes were rejected during iteration due to large arrival time residuals or large condition numbers, i.e., poorly constrained earthquake locations. Earthquakes with negative epicentral depth were also excluded during relocation. Finally, the travel time residual was not allowed to exceed $0.3 \mathrm{sec}$ in the last iteration.

Earthquakes recorded by the TTSN were located using the 1-D velocity model (Fig. 2) proposed by Yeh and Tsai (1981). Their 1-D velocity model was obtained by inverting P-wave arrival times in central Taiwan. There are significant differences in crustal structures between central and northern Taiwan. Since 1995, a revised 1-D velocity model proposed by Chen (1995) was adapted by the CWB for island-wide routine earthquake location. The 1-D model of Chen (1995), which includes more crustal discontinuities than that of Yeh and Tsai (1981) (Fig. 2), has been used for JHD relocation in this study.

Results of JHD analysis are summarized in Fig. 3. Map and cross-sectional views of original hypocenters in the Tatun region are shown in Figs. 3a, c and e. Those of JHD relocated hypocenters are shown in Figs. 3b, $\mathrm{d}$ and $\mathrm{f}$. After the JHD relocation, earthquake hypocenters are in general more clustered than the original TTSN catalog locations. Clustered seismicity trends with inconsistent dipping directions are manifest (Figs. 3d, f). In particular, a dominant linear southeast dipping seismicity trend is readily identifiable from the relocated seismicity.

We have reviewed TTSN earthquake catalog to explore the characteristic features of local seismicity in the Tatun volcano region. Particular attentions have been paid to the clustered earthquake sequences both in time and in space. Two remarkable sequences are readily spotted, one occurred on June 11, 1988, and the other on July 3, 1988. The first sequence has been selected because it includes more events than any other clustered earthquake sequences. The 


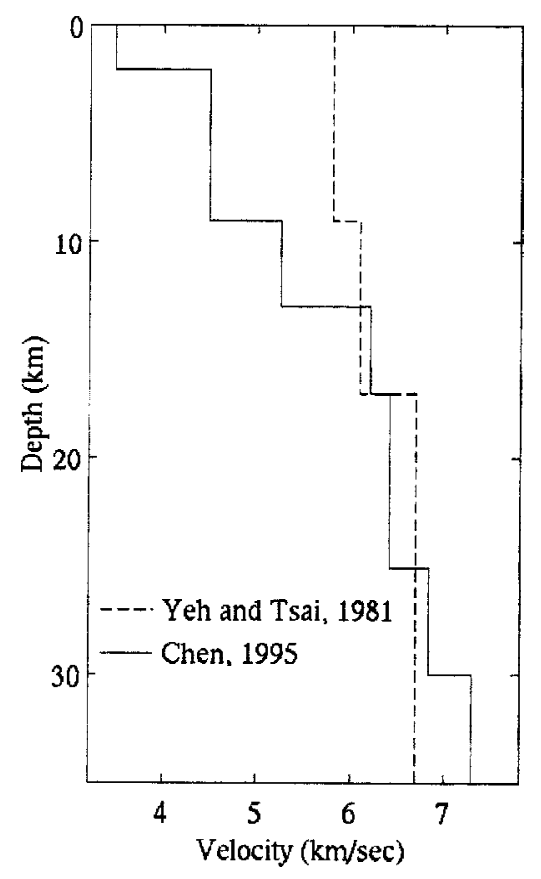

Fig. 2. One-dimensional $V_{P}$ models in the study area proposed by Yeh and Tsai (1981) (dashed line) and Chen (1995) (solid line). A $V_{P} / V_{S}$ ratio of 1.73 is assumed in both models.

sequence was composed of 13 earthquakes with the largest ones with magnitude 3.1. This earthquake sequence followed neither the Omori law for a typical aftershock-decay (Utsu 1961) nor an apparent mainshock (Fig. 4a). Relocated hypocenters are very close to each other forming a very tight cluster (Figs. 3b, d). The episode, a sequence of events closely clustered in time and space without an apparent mainshock, is a typical feature of swarm activity frequently observed in hydrothermal systems. The second sequence has been selected because it started with a magnitude 5.1 earthquake, which is the largest one in the Tatun volcano region during the TTSN and TSN operation period. The sequence presents a disparate phenomenon. It consists of a typical mainshock-aftershock pattern, initiated with an $\mathrm{M}=5.1$ main event and followed by a few smaller aftershocks (Fig. 4b). The sequence is distributed over a larger source area than the first sequence is. The clustered hypocenters of the second sequence define potentially an active fault that dips differently from the background seismicity.

\subsection{Similar Waveforms Observed from Continuous Data}

Earthquake swarms related to magma intrusion or hydrothermal activities have been observed frequently in active volcano regions (Sykes 1970). It is, however, not an easy task to identify any earthquake swarm activity and to determine reliable hypocenters in the Tatun 

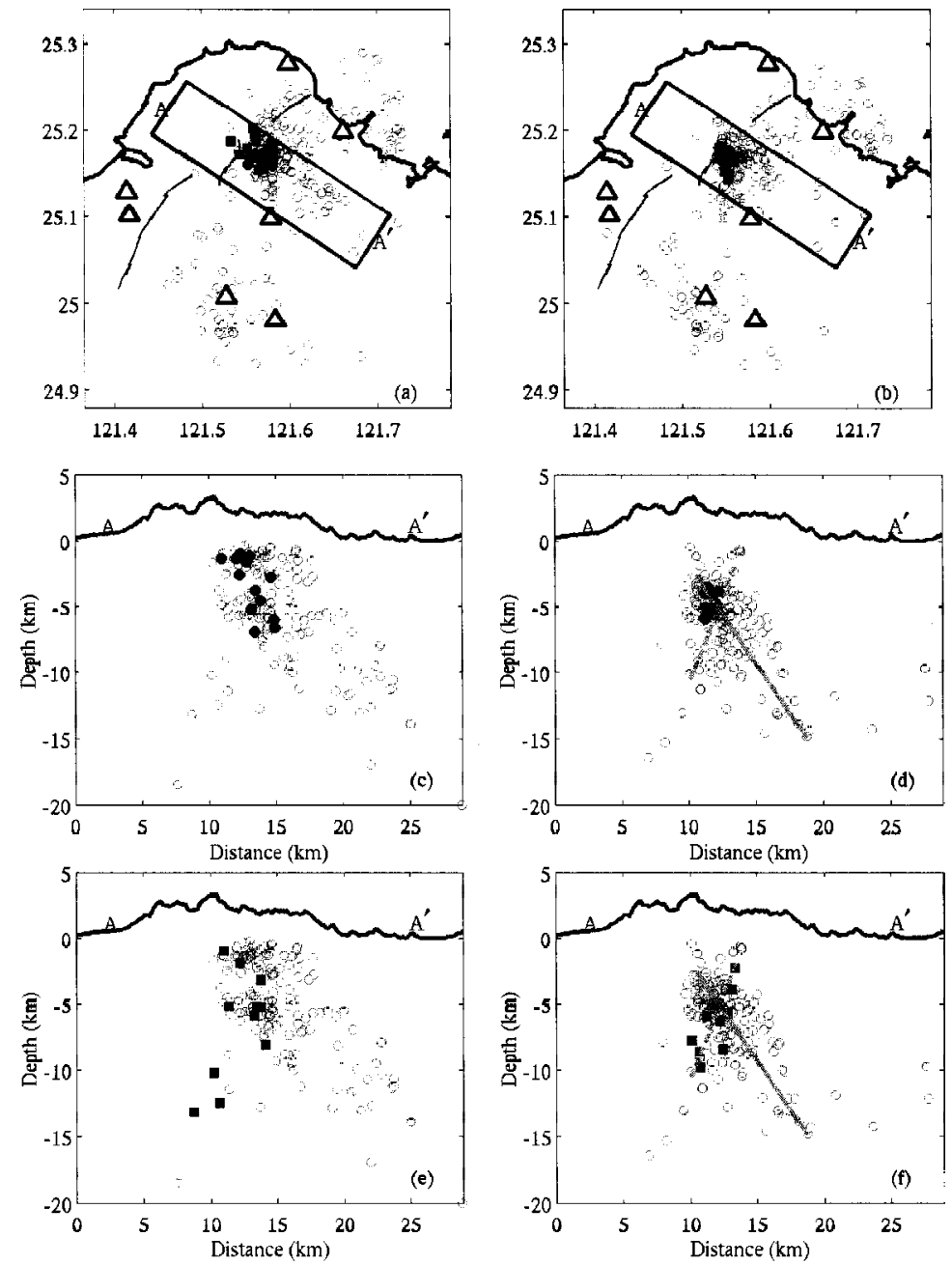

Fig. 3. Earthquake hypocenters selected for JHD analysis in the Tatun volcano region. Open triangles are TTSN stations in the Tatun volcano area. Active faults in the area are marked by solid lines. Map views of earthquake hypocenters (open circles) determined by TTSN-IES and JHD relocation are shown in (a) and (b), respectively. Earthquake hypocenters along A-A' determined by TTSN-IES are shown by open circles in (c) and (e), and those by JHD relocation technique are shown in (d) and (f). Earthquake hypocenters on June 11, 1988 sequence are shown by solid circles (a, b, c and d). Earthquake hypocenters during the sequence on July 3, 1988 are shown by solid rectangles ( $a, b$, e and f). Both earthquake sequences are tightly clustered after the relocation ( $\mathrm{d}$ and $\mathrm{f}$ ). Potential subsurface structures are shown by gray lines. Topography on top of hypocenter profile is vertically exaggerated $(\times 3)$ to show elevation change along A-A'. 

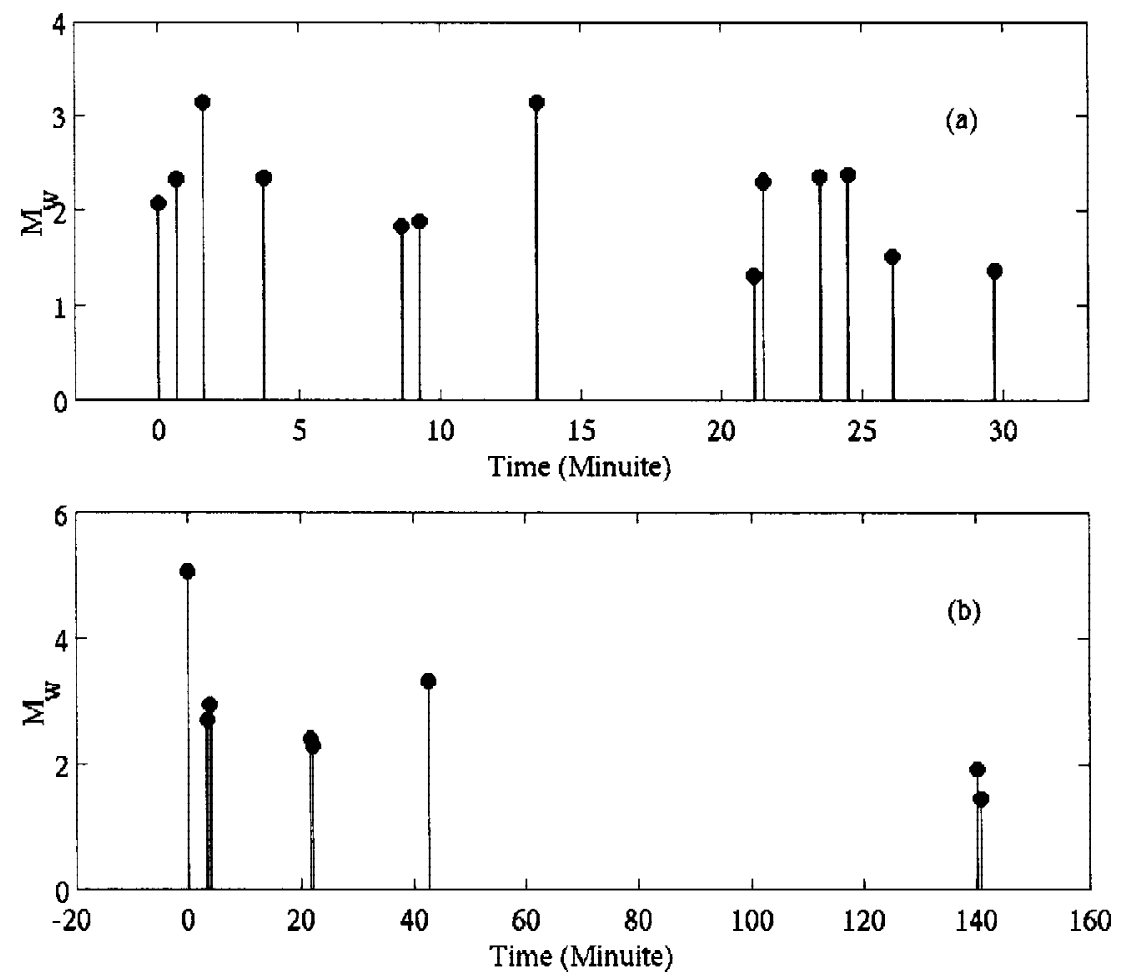

Fig. 4. Magnitude-time distribution of two earthquake sequences showing (a) a sequence of earthquakes on June 11, 1988 with no apparent mainshock that represents a typical earthquake swarm, and (b) the other sequence of earthquakes on July 3, 1988 initiated with a $\mathrm{M}_{\mathrm{W}}=5.06$ event and followed by many smaller aftershocks that represents a typical mainshockaftershock sequence.

volcano region, since so few seismic stations are available in the study area under the previous TTSN and the current TSN configurations. Thus, we revisited continuous seismograms recorded at a few BATS stations around a few local crust earthquakes reported in the CWB catalog.

For example, we examined continuous broadband data around a sequence of earthquakes that occurred on May 10, 1998. There were three events with magnitudes of 3.1 (EV1), 2.0 (EV2), and 2.3 (EV3), which occurred sequentially (Fig. 5). The first event and the third event occurred about 73 minutes apart. We examined four hours of continuous data at the ANPB station, two hours before and two hours after the $M=3.1$ earthquake. The ANPB station is located in the center of the Tatun volcano region. More than 40 micro-earthquakes not previously reported in the CWB catalog can be identified before and after the 3.1 event (EV1). Many of these events have very low signal-to-noise ratio due to their small magnitude and high background noise typical in any volcanic region. Figure 6 shows bandpass filtered verti- 


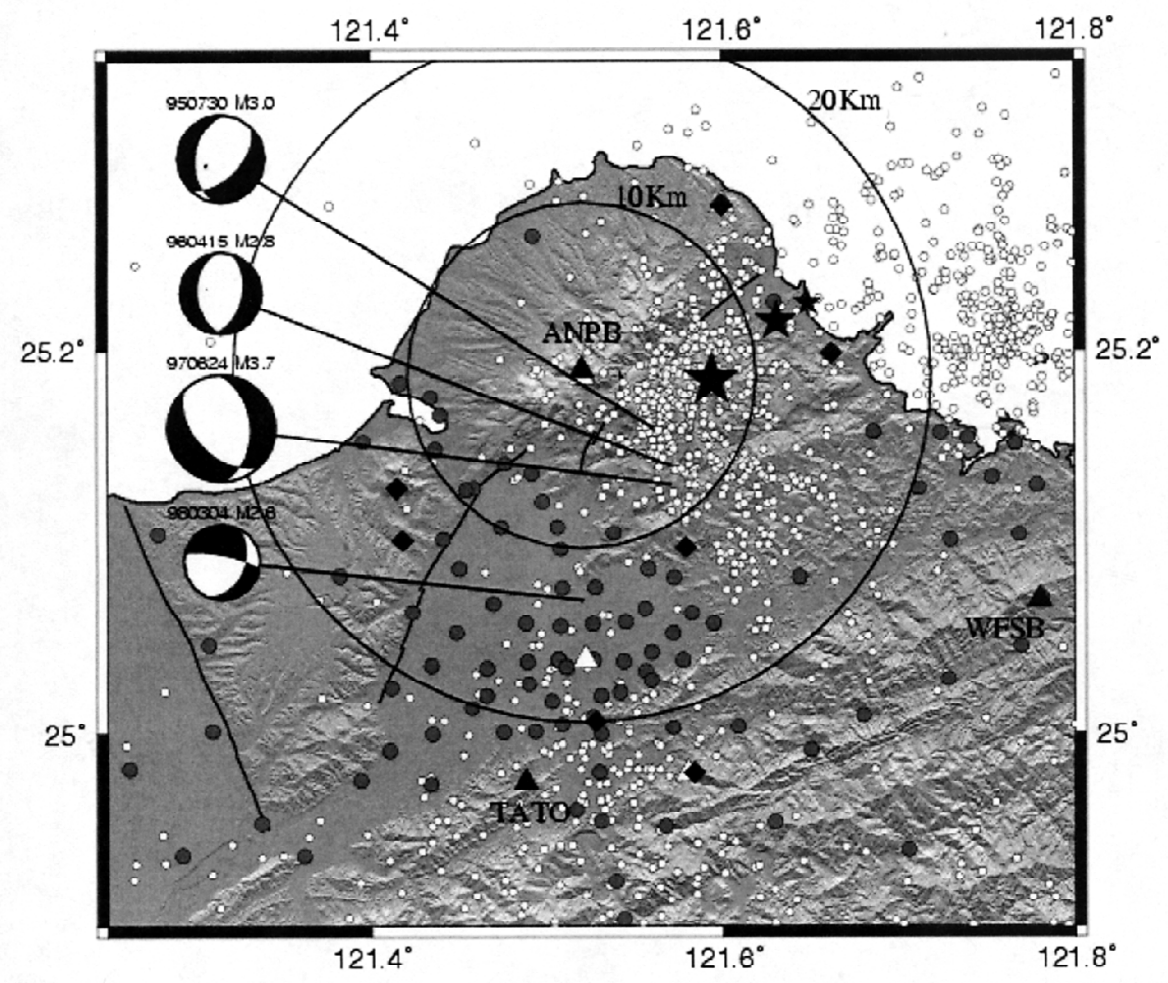

Fig. 5. Locations of three earthquakes (solid stars) that occurred on May 10, 1998. Two circles with radius of $10 \mathrm{~km}$ and $20 \mathrm{~km}$ from ANPB station are shown for reference. Based on the arrival time differences between the P-and S-arrivals, the distances between observing station (ANPB) and earthquake hypocenters are about $10 \mathrm{~km}$. Also shown are selected focal mechanisms determined by first arriving polarities observed by TSN and TSMIP stations. Most earthquakes in the region ruptured in the normal faulting sense. Symbols in this figure are the same as those shown in Fig. 1.

cal component traces in the ranges from 4 to $10 \mathrm{~Hz}$ for 30 events observed at ANPB station. The waveforms of these bandpass filtered seismograms are similar indicating that hypocenters and focal mechanisms of these earthquakes must be very similar or clustered undergoing similar regional stress. We have also inspected continuous seismograms at two other nearby BATS stations, TATO and WFSB, which are located at 24 and $29 \mathrm{~km}$ distance from ANPB, respectively. The ultimate goal was to explore if any of these earthquakes were recorded by at least three BATS stations so as to be locatable. Unfortunately, magnitudes of these previously un-reported events were too small to be visible at TATO and WFSB stations. However, the time differences between the $\mathrm{P}$ and $\mathrm{S}$ arrivals of these previously unidentified earthquakes are about 1.3 seconds, corresponding approximately to $10 \mathrm{~km}$ from the recording station, assum- 


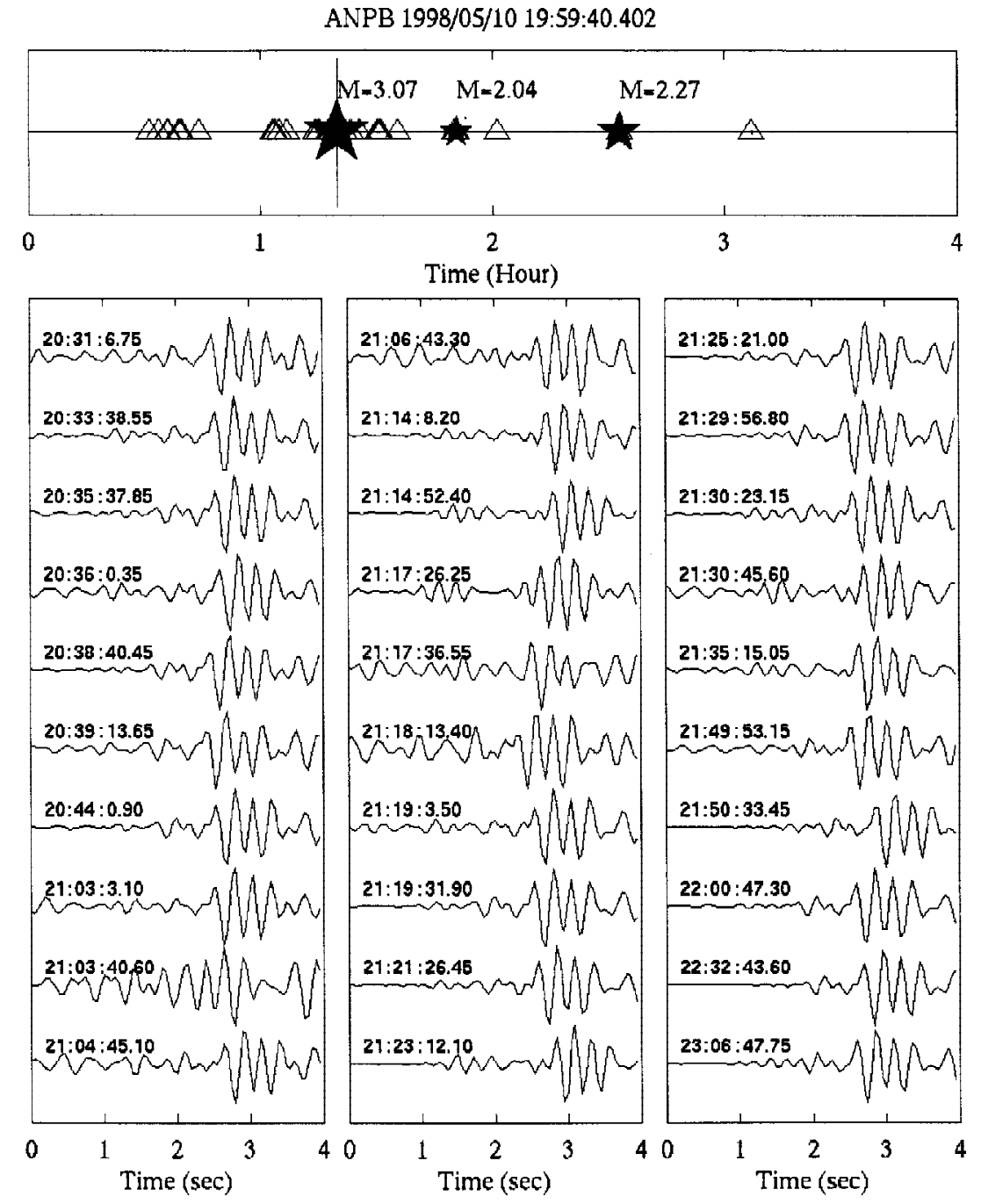

Fig. 6. Four hours time history of continuous data (vertical component) recorded at BATS-ANPB (upper panel) showing the occurrence of many microearthquakes not reported in the CWB catalog (open triangles) and three larger earthquakes (solid stars) that were reported in the CWB catalog. Examples of thirty bandpass filtered $(4-10 \mathrm{~Hz})$ vertical component seismograms for the newly identified earthquakes are shown in the lower panels. P-wave arrival time is shown in the upper-left corner of each trace. 
ing a homogeneous P-wave velocity of $5.8 \mathrm{~km} \mathrm{~s}^{-1}$ and a $V_{P} / V_{S}$ ratio of 1.73 . A circle with a radius of $10 \mathrm{~km}$ around the ANPB station is shown to portray a potential source region of micro-seismicity recognized in this study (Fig. 5).

The three earthquakes (EV1, EV2, and EV3) in the CWB catalog were recorded at ANPB with high signal-to-noise ratios. Their waveforms are very similar to each other with correlation coefficients of $0.87,0.97$ and 0.92 for pairs between EV1 and EV2, EV1 and EV3, and EV2 and EV3, respectively (Fig. 7). High correlation coefficients among these three events strongly suggest that their hypocenters should be very close to each other. However, earthquake epicenters reported in the CWB catalog are far apart (Fig. 5). Since the first event is the largest among the three, it was recorded by more seismic stations than the other two. Thus it is reasonable to assume that the epicenter of the first event $(\mathrm{M}=3.1)$ is better determined than the other two. The first event is located within the $10 \mathrm{~km}$ radius circle (Fig. 5), which is consistent with the observed travel time difference between the P and S-arrivals. In other word, locations of the other two events (EV2 and EV3) may have been seriously mislocated in the CWB catalog. The mislocation of earthquake hypocenters can be easily attributed to poor station coverage, errors in phase arrival reading, and most importantly to an over-simplified $1-\mathrm{D}$ velocity model from the very complicated earth structure beneath the Tatun volcano region.

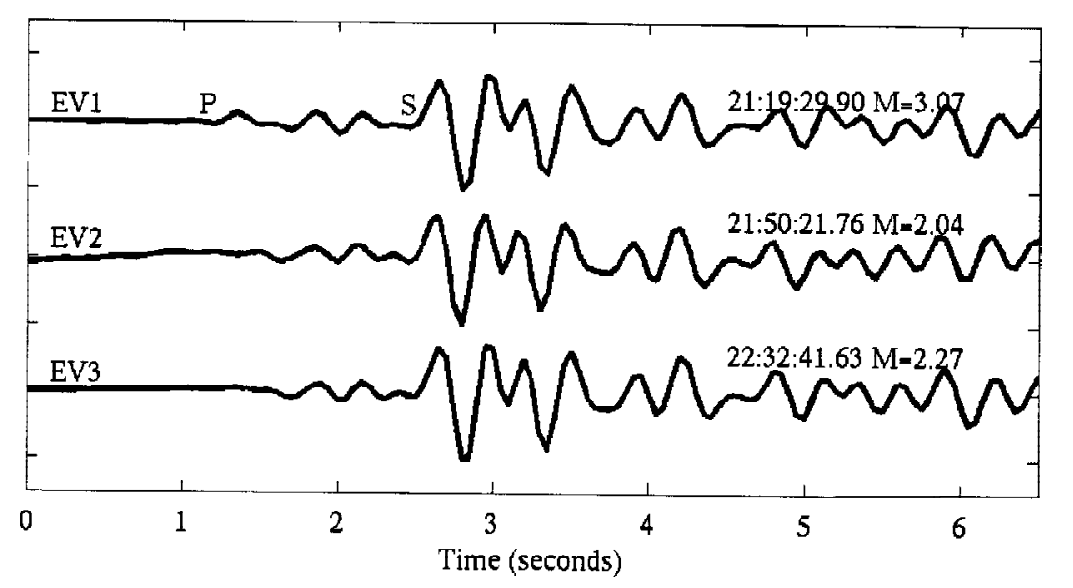

Fig. 7. Vertical component waveforms of BATS-ANPB for the three earthquakes reported by CWB (solid stars in Figs. 5 and 6 ) after applying a bandpass filter $(0.1-8 \mathrm{~Hz})$. Their origin times and magnitude determined by CWB are shown in the upper-right corner of each trace. Arrival time differences between the direct $\mathrm{P}$ - and $\mathrm{S}$-waves are about 1.3 second for all three events. Direct $\mathrm{S}$-wave arrival times were read from two horizontal components (not shown in this figure). Waveforms are very similar to each other. Cross-correlation coefficients for waveform pairs of EV1 and EV2, EV1 and EV3, and EV2 and EV3 are 0.86, 0.97 and 0.92, respectively. 


\subsection{Anomalous B-value}

One of the fundamental earthquake scaling relationships is the relation between earthquake size and frequency of occurrence, historically known as the Gutenberg-Richter relation (Gutenberg and Richter 1942). In general, b-values are between 2/3 and 1. Observations over a long period of time and a wide range of tectonic settings indicate this type of power-law distribution arises from the self-similarity of earthquakes. Abnormal b-values $(>1.0)$ are most frequently reported for areas with abundant of earthquake swarms. The most favored explanation for the abnormally high b-value is a weak crust incapable of sustaining high strain and heterogeneous stress (Lay and Wallace 1995; Scholz 2002).

After we identified numerous small earthquake sequences discussed in the previous section, we suspected whether our observation is only a transient incident. If the observation is not a temporary phenomenon, we might expect to observe a representative seismicity-frequency relationship from the b-value analysis of background seismicity in the area. We computed b-values of the entire Taiwan and the Tatun volcano group for shallow earthquakes (depth $<30 \mathrm{~km}$ ) from the TTSN catalog between 1973 and 1990 and CWB earthquake catalog since 1991. There are spatial and temporal variations in the completeness $\left(\mathrm{M}_{\mathrm{C}}\right)$ of earthquake magnitude in the catalog. The software package ZMAP (Wiemer 2001) is used to analyze spatial variations of $\mathrm{b}$-value and the completeness $\left(\mathrm{M}_{\mathrm{C}}\right)$ of the earthquake catalog. The magnitude threshold of catalog completeness is chosen at the lowest magnitude for which magnitude-frequency relation remains a straight line. We also counted the number of earthquakes in every 0.1 magnitude bins and observed the increase of frequency with decreasing magnitude. The linear magnitude-frequency relation fails below the estimated $\mathrm{M}_{\mathrm{C}}$. Following the standard practice described above, results from the analysis indicate that $\mathrm{M}_{\mathrm{C}}=2.1$ is appropriate for a reliable estimation of $b$-values for the entire Taiwan region and the Tatun volcano area. The b-value for all of Taiwan is estimated to be 0.94 (Fig. 8). The b-value obtained for the Tatun volcano region is around 1.22 that is significantly higher than the $\sim 0.94$ overall $b$-value. The estimated b-values varied less than \pm 0.05 over different magnitude ranges for all of Taiwan and the Tatun volcano area. Wang (1988) also obtained high b-value for shallow earthquakes in the Tatun volcano region using earthquakes during 1973 and 1984. The comparison of b-values between the Tatun volcano region and the entire Taiwan area confirms that our observation of numerous clustered small earthquakes or earthquake sequences is a persistent phenomenon in the Tatun volcano region at least during the modern seismic instrument period. The significantly high b-value in the Tatun volcano region reveals further that seismicity in the region is governed by the collapse of weak crust associated with the hydrothermal/volcano-related activities in the region.

\subsection{Earthquake Focal Mechanisms}

It appears that seismicity in the Tatun volcano region can be grouped into two different types including small to moderate magnitude tectonic earthquakes (e.g., an earthquake sequence on 1988/07/03) associated with regional tectonic process and swarm type micro-earthquakes (e.g., an earthquake sequence on 1988/06/11) associated with hydrothermal activity or 


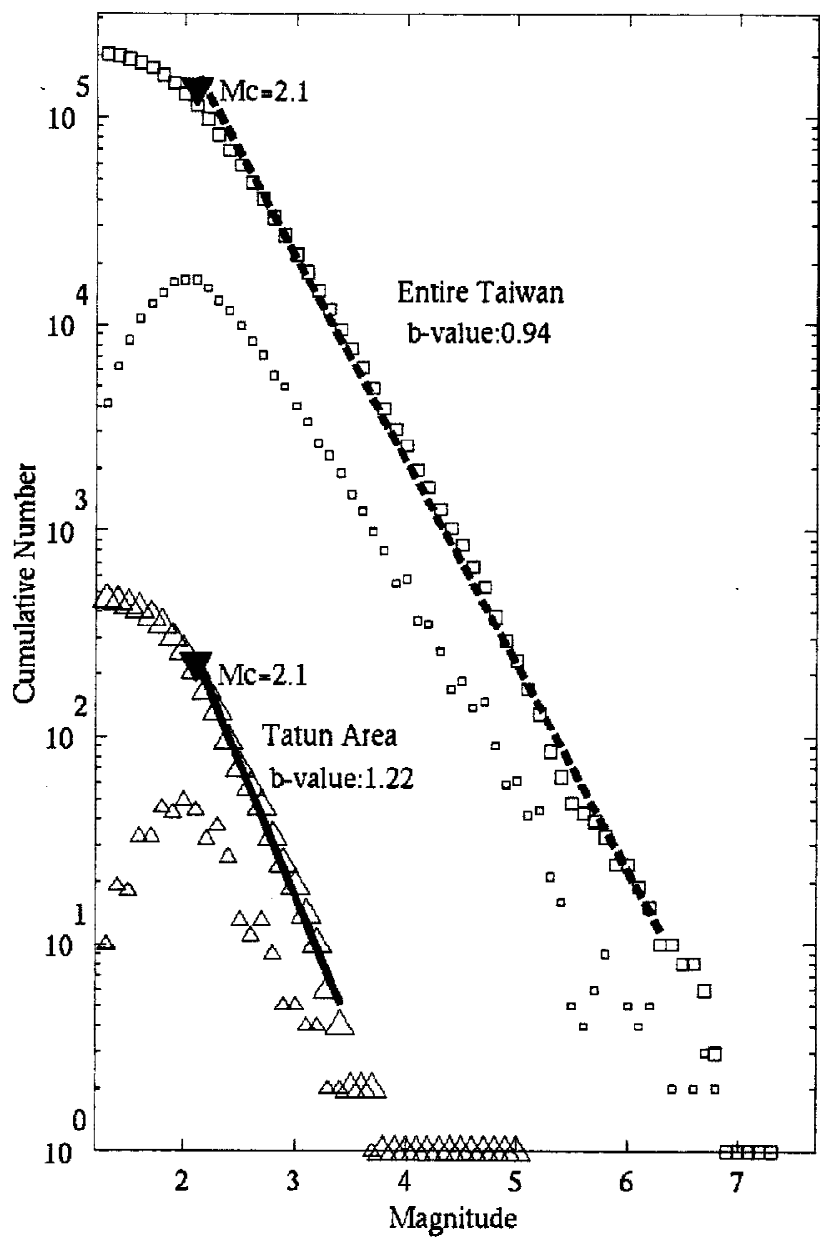

Fig. 8. Comparison of frequency-magnitude distribution for the entire Taiwan region and for the Tatun volcano region. For shallow seismicity less than $30 \mathrm{~km}$ covering the entire island of Taiwan, the estimated b-value is 0.94 shown by the broken line. This value is approximately the average observed at many different tectonic settings. Larger squares show the cumulative number of earthquakes with magnitude and smaller squares show the number of earthquakes in 0.1 magnitude bins. The b-value is 1.22 for the Tatun volcano area (solid line). The significantly high b-value indicates that the crust beneath the Tatun volcano group is weak and cannot sustain high strain levels. Seismicity in the area is probably governed by potential hydrothermal/volcano structures. Larger triangles show the cumulative number of earthquakes and smaller squares show the number of earthquakes in 0.1 magnitude bins in the Tatun volcano region earthquakes. 
potential magma reservoirs. We noticed that information in both TTSN and CWBSN catalogs are not enough for focal mechanism determinations using first arrival polarities. We selected 24 earthquakes with magnitude larger than 2.5 and focal depth shallower than $30 \mathrm{~km}$ during the period of TSMIP operation since 1991 to obtain additional first arrival polarity information. Most selected events either have not enough clear first arrivals or produced less reliable focal mechanism solutions. Focal mechanisms of four earthquakes determined using P-wave first motion information from the TSN and TSMIP stations are presented in Fig. 6. It is apparent that the focal mechanisms in the Tatun volcano region are predominantly normal faulting. $\mathrm{Yu}$ et al. (1999) conducted repeated GPS survey in the Taipei basin between 1991 and 1996. They found that the area is under extensional environment, which is consistent with the general trend of focal mechanism solutions determined in this study. The hydrothermal/magmatic activities along the volcanic arc behind the subduction system in the northeastern Taiwan region are most probably responsible for the occurrence of these normal faulting earthquakes in an extensional environment.

\section{CONCLUSIONS}

We have investigated various seismological data collected since 1973 in the Tatun volcano region of northern Taiwan to investigate corresponding seismicity patterns. Earthquake hypocenters are more tightly clustered after relocation using the JHD technique. Apparently, earthquakes in the region can be grouped into two different types including tectonic earthquakes related to active faults and extensional stress environment and swarm-type earthquakes associated with hydrothermal or magmatic activities. A significantly high b-value in the Tatun volcano region also implies that seismicity in the region is governed by potential hydrothermal or volcano-related activities in a weak crust. There is much more swarm-type earthquake activity in the Tatun volcano region than was reported in the CWB catalog. The existing seismic network coverage in the Tatun volcano region is so poor that not only many local earthquakes are mislocated but also many micro-earthquakes are not detected and not locatable. Therefore, it is essential to improve the spatial coverage and spatial resolution of the seismic monitoring system in the Tatun volcano region for effective and meaningful seismological study. Preliminary seismic tomographic study of the Tatun volcano region using data of limited spatial resolution (Kim 2003; Kim et al. 2005) reveals that there is an anomalous region of low Vp and high $\mathrm{Vp} / \mathrm{Vs}$ ratio at depths from 6 to $10 \mathrm{~km}$ beneath the Tatun Volcano, an indication of possible partial molten materials or magma reservoir. Therefore, the widely distributed hydrothermal activity and gas fumaroles, the frequently observed swarm-type and tectonic earthquakes, and the potential of magma reservoirs in the Tatun volcano region pose the possibility of seismic and volcanic hazard for the adjacent Taipei metropolitan area. Although there is no immediately threat of volcanic activity at the Tatun volcano region, apparent signs related to potential volcanic activity should be seriously evaluated and monitored. While current seismic monitoring in the Tatun volcanic region is not adequate in providing high-resolution images of subsurface structures nor for a comprehensive study of seismic activity, a longterm dense seismic array monitoring system covering the entire region is definitely needed for 
the studies of background seismicity, regional velocity structure, attenuation of regional seismic waves, and the geometry and boundary of potential hydrothermal/magmatic structures in the region. Such studies are essential for a comprehensive assessment of volcanic/seismic hazard pertinent to the safety of the population in the Taipei metropolitan area.

Acknowledgements We thank Dr. Yi-Ben Tsai for helpful discussions on TTSN data. We also thank Dr. Jose Pujol for making his JHD package available for this study. A software package to analyze seismicity, ZMAP, has been used for b-value study (Wiemer 2001). Two figures were made using the GMT (Generic Mapping Tools) software (Wessel and Smith 1991). We appreciate Dr. Yung-Hsi Lee and two anonymous reviewers for constructive comments. One of the authors (K. H. K.) was supported by the Ministry of Education, Taiwan, under University Academic Excellence - Research on Seismo-Electromagnetic Precursors of Earthquake through National Central University and by the National Science Council, under grants NSC93-2119-M-001-016, through the Institute of Earth Sciences, Academia Sinica for his post-doctoral research. This is CERI contribution number 493.

\section{REFERENCES}

Angelier, J., H. T. Chu, and J. C. Lee, 1997: Shear concentration in a collision zone: kinematics of the Chihshang Fault as revealed by outcrop-scale quantification of active faulting, Longitudinal Valley, eastern Taiwan. Tectonophys., 274, 117-143.

Chen, Y. L., 1995: Three-dimensional velocity structure and kinematic analysis in the Taiwan area, $\mathrm{PhD}$ thesis, Nat. Central Univ., 172pp.

Gutenberg, B., and C. F. Richter, 1942: Earthquake magnitude, intensity, energy, and acceleration. Bull. Seism. Soc. Am., 32, 163-191.

Ho, C. S., 1988: An Introduction to the Geology of Taiwan Explanatory Text of the Geologic Map of Taiwan, Central Geol. Survey/The Ministry of Econ. Affairs.

Kim, K. H., 2003: Subsurface structure, seismicity patterns, and their implication to tectonic evolution in Taiwan. PhD thesis, CERI. Memphis, Univ. Memphis, 159pp.

Kim, K. H., J. M. Chiu, H. Kao, Q. Liu, and Y.-H. Yeh, 2004: A preliminary study of crustal structure in Taiwan region using receiver function analysis. Geophys. J. Int., 159, 146164.

Lay, T., and T. C. Wallace, 1995: Modern Global Seismology, Acad. Press.

Lee, C. T., 1999: Neotectonics and active fault in Taiwan. Workshop on Disaster Prevention/ Man. \& Green Tech., Foster City, CA, USA.

Pujol, J., 1988: Comments on the joint determination of hypocenters and station corrections. Bull. Seism. Soc. Am., 78, 1179-1189.

Pujol, J., 1995: Application of the JHD technique to the Loma Prieta, California, mainshockaftershock sequence and implications for earthquake location. Bull. Seism. Soc. Am., 85, 129-150. 
Pujol, J., 2000: Joint Event Location - The JHD technique and applications to data from local seismic networks. In: Thurber, C. H., and N. Rabinowitz, (Eds.), Advances in Seismic Event Location. Kluwer Acad. Publishers, 163-204.

Scholz, C. H., 2002: The mechanics of earthquakes and faulting, Cambridge Univ. Press.

Song, S. R., S. Tsao, and H. J. Lo, 2000: Characteristics of the Tatun volcanic eruptions, north Taiwan; implications for a cauldron formation and volcanic evolution. J. Geol. Soc. China, 43, 361-378.

Suppe, J., 1984: Kinematics of arc- continent collision, flipping of subduction, and back-arc spreading near Taiwan. Mem. Geol. Soc. China, 6, 21-33.

Sykes, L. R., 1970: Earthquake swarms and sea-floor spreading. J. Geophys. Res., 75, 65986611.

Tsai, Y. B., 1986: Seismotectonics of Taiwan. Tectonophys., 125, 17-37.

Tsai, Y. B., Y. H. Yeh, Z. S. Liaw, T. W. Lee, and M. T. Lin, 1981: Seismological evidence of an active plate boundary in the Taiwan area, Mem. Geol. Soc. China, 4, 143-154.

Utsu, T., 1961: A statistical study on the occurrence of aftershocks. Geophys. Mag., 30, 521605.

Wang, J. H., 1988: b values of shallow earthquakes in Taiwan. Bull. Seism. Soc. Am., 78, 1243-1254.

Wessel, P., and W. H. F. Smith, 1991: Free software helps map and display data.Eos, 72, 441, 445-446.

Wiemer, S., 2001: Electronic seismologist: a software package to analyze seismicity: ZMAP. Seism. Res. Lett., 72, 373-382.

Yeh, Y. H., and Y. B. Tsai, 1981: Crustal structure of central Taiwan from inversion of Pwave arrival time. Bull. Inst. Earth Sci., Acad Sinica, 1, 83-102.

Yu, S. B., H. Y. Chen, L. C. Kuo, C. S. Hou, and J. F. Lee, 1999: A study on the fault activities of the Taipei basin, Central Geological Survey, Ministry of Economic Affairs, Republic of China, 227-251.

Yu, S. B., H. Y. Chen, L. C. Kuo, S. E. Lallemand, and H. H. Tsien, 1997: Velocity field of GPS stations in the Taiwan area. Tectonophys., 274, 41-59.

Yu, S. B., and C. C. Liu, 1989: Fault creep on the central segment of the Longitudinal Valley Fault, eastern Taiwan. Proc. Geol. Soc. China, 32, 209-231. 